\title{
Flexible Lösungen in der Schleuderrad-Strahltechnik
}

Eür das Schleuderstrahlen sollten einzelne Baugruppen und ganze Maschinen so ausgelegt sein, dass sie schnell an neue Ansprüche angepasst werden können. Unter dem Motto „Flexible Lösungen in der Schleuderrad-Strahltechnik" zeigt Agtos zum am Beispiel einer Hochleistungsturbine (TA 3.6.8), wie diese schnell auf verschiedene Materialien umgerüstet werden kann. Da die Turbinen mit einem Einscheiben-Schleuderrad bestückt sind, entfallen die sonst üblichen Distanzbolzen. Damit wird die Zahl der Verschleißteile im Schleuderrad gesenkt. Die Anwender profitieren von weniger Wartungsaufwand und vom besseren Strahlmittelfluss. Ein Verteilerrad übernimmt die mechani- sche Vorbeschleunigung des Strahlmittels. Mit der Leithülse lässt sich der Strahlbereich von außen leicht einstellen. Die Turbinenschaufeln des Schleuderrades sind leicht zu wechseln. Die Hochleistungsturbinen werden bis zu einer bestimmten Baugröße durch direkt angeflanschte Drehstrommotoren, Schutzart IP54, angetrieben. Eine spezielle Labyrinth-Abdichtung am Turbinengehäuse verhindert das Eindringen von Staub oder Strahlmittel in die Motorlagerung.

Tel. 02572 96026-0, www.agtos.de

Halle 3, Stand D 13(3)

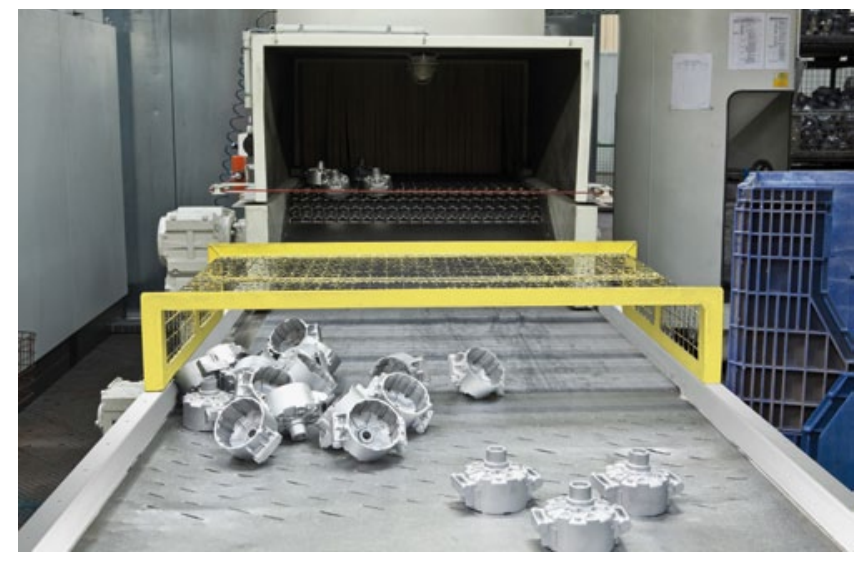

\section{Neue Pumpenserie für die Nasslackierung}

W agner stellt in Hannover unter anderem eine neue Serie an Finishing-Pumpen für die Nasslackierung vor, die sich durch Langlebigkeit, Zuverlässigkeit und Vielseitigkeit auszeichnen. Die Pumpen eignen sich ideal für das gesamte Spektrum industrieller Anwendungen, angefangen vom Kleinbetrieb bis hin zu Großindustrieanlagen. Neue technologische Merkmale der Pumpen ermöglichen es, die Beschichtungsabläufe zu optimieren und die laufenden Kosten auf ein Minimum zu reduzieren.

Tel. 07544 505-0, www.wagner-group.com

Halle 3, Stand D 13(9)

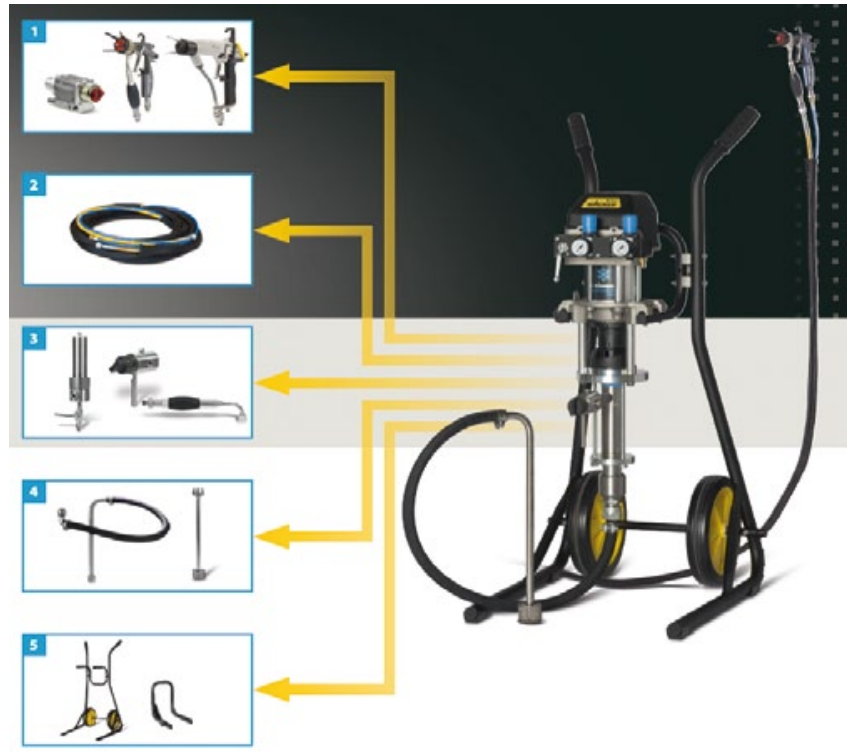

\section{Prüfgerät zur Beurteilung} der Waschbeständigkeit und Reinigungsfähigkeit von

\section{Beschichtungen}

D er Messgerätehersteller Erichsen stellt in Hannover auf dem VDMA-Gemeinschaftsstand ein neues Waschbarkeits- und Scheuerprüfgerät (494 MC) vor, ein weiterentwickeltes Nachfolgemodell des bis dato etablierten Modells 494. Das neue Gerät gestattet durch seine einstellbaren Prüfparameter, auch weit über den üblichen Normenbereich hinaus verlässliche, individuell bedarfsgerecht angepasste Prüfmethodik bei komfortabler Bedienung. Das Gerät unterscheidet sich gegenüber dem Vorgängermodell durch einige wesentliche Merkmale: So sind bis zu drei Prüfbahnen gleichzeitig ohne weiteren Adapter möglich - ein Erweiterungsadapter für insgesamt bis zu sechs Prüfbahnen ist in Entwicklung. Das Gerät ermöglicht eine vereinfachte Bedienung über Tastenfeld und Display und verfügt über Parameterspeicher für 20 Prüfabläufe. Der Hubweg ist einstellbar von 10 bis $300 \mathrm{~mm}$. Die Hubrate ist je nach gewähltem Hubweg zwischen 5 und 70 Doppelhübe/ min einstellbar. Tel. 02372 9683-43, www.erichsen.de Halle 3, Stand D 13(8)

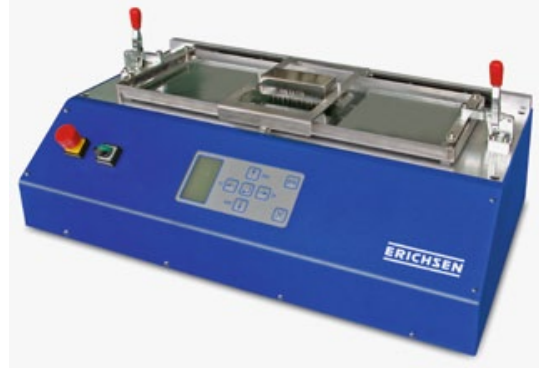

